\title{
Secondary prevention of type 1 diabetes mellitus: stopping immune destruction and promoting $\beta$-cell regeneration
}

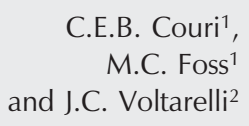

\author{
${ }^{1}$ Divisão de Endocrinologia and Metabologia, \\ 2Divisão de Imunologia Clínica e Unidade de Transplante de Medula Óssea, \\ Departamento de Clínica Médica, Faculdade de Medicina de Ribeirão Preto, \\ Universidade de São Paulo, Ribeirão Preto, SP, Brasil
}

\section{Correspondence \\ J.C. Voltarelli \\ Hemocentro Regional de \\ Ribeirão Preto \\ Campus da USP \\ 14051-140 Ribeirão Preto, SP \\ Brasil \\ Fax: +55-16-2101-9309 \\ E-mail: jcvoltar@fmrp.usp.br \\ Research supported by FAEPA-HCRP, FUNDHERP, FAPESP, CNPq, and FINEP.}

Received September 30, 2005 Accepted July 11, 2006

\begin{abstract}
Type 1 diabetes mellitus results from a cell-mediated autoimmune attack against pancreatic $\beta$-cells. Traditional treatments involve numerous daily insulin dosages/injections and rigorous glucose control. Many efforts toward the identification of $\beta$-cell precursors have been made not only with the aim of understanding the physiology of islet regeneration, but also as an alternative way to produce $\beta$-cells to be used in protocols of islet transplantation. In this review, we summarize the most recent studies related to precursor cells implicated in the regeneration process. These include embryonic stem cells, pancreasderived multipotent precursors, pancreatic ductal cells, hematopoietic stem cells, mesenchymal stem cells, hepatic oval cells, and mature Bcells. There is controversial evidence of the potential of these cell sources to regenerate $\beta$-cell mass in diabetic patients. However, clinical trials using embryonic stem cells, umbilical cord blood or adult bone marrow stem cells are under way. The results of various immunosuppressive regimens aiming at blocking autoimmunity against pancreatic $\beta$-cells and promoting $\beta$-cell preservation are also analyzed. Most of these regimens provide transient and partial effect on insulin requirements, but new regimens are beginning to be tested. Our own clinical trial combines a high dose immunosuppression with mobilized peripheral blood hematopoietic stem cell transplantation in early-onset type 1 diabetes mellitus.
\end{abstract}

\section{Introduction}

Diabetes mellitus is a metabolic syndrome characterized by hyperglycemia resulting from defects in insulin secretion, insulin action, or both. Chronic hyperglycemia is associated with long-term damage, dysfunction and failure of various organs, including retinopathy with potential loss of vision; nephropathy leading to renal failure; peripheral
- Diabetes mellitus

- ß-cell regeneration

- ß-cell preservation

- B-cell precursors

- Immune intervention

- Stem cell
Key words

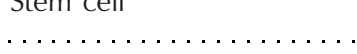

(n)


creatic B-cells. Autoimmune destruction of $ß$-cells is due to multiple genetic predispositions and is also related to environmental factors that are still poorly defined (1). When clinical symptoms are observed the autoimmune process is markedly advanced (60$80 \%$ of the $\beta$-cell mass have been destroyed at the time of diagnosis (2)). The rate of $\beta$ cell destruction is variable, being rapid in children and slow in adults (3) (Figure 1). In the later stage of disease there is little or no insulin secretion, as indicated by low or undetectable plasma levels of C-peptide. Cpeptide is consecrated with insulin by the $\beta$ cells as a by-product of the enzymatic cleavage of proinsulin to insulin. Measurement of C-peptide provides a fully validated means of quantifying endogenous insulin secretion, being closely related to the amount of B-cell mass (4). Patients with type 1 diabetes depend on exogenous insulin administration for survival. The best classical treatment is based on 3-4 subcutaneous injections of insulin per day, i.e., intensive insulin therapy (5). This treatment is responsible for a 35$90 \%$ reduction of the risk of retinopathy, nephropathy and neuropathy compared with conventional therapy with 1-2 injections per day (6).

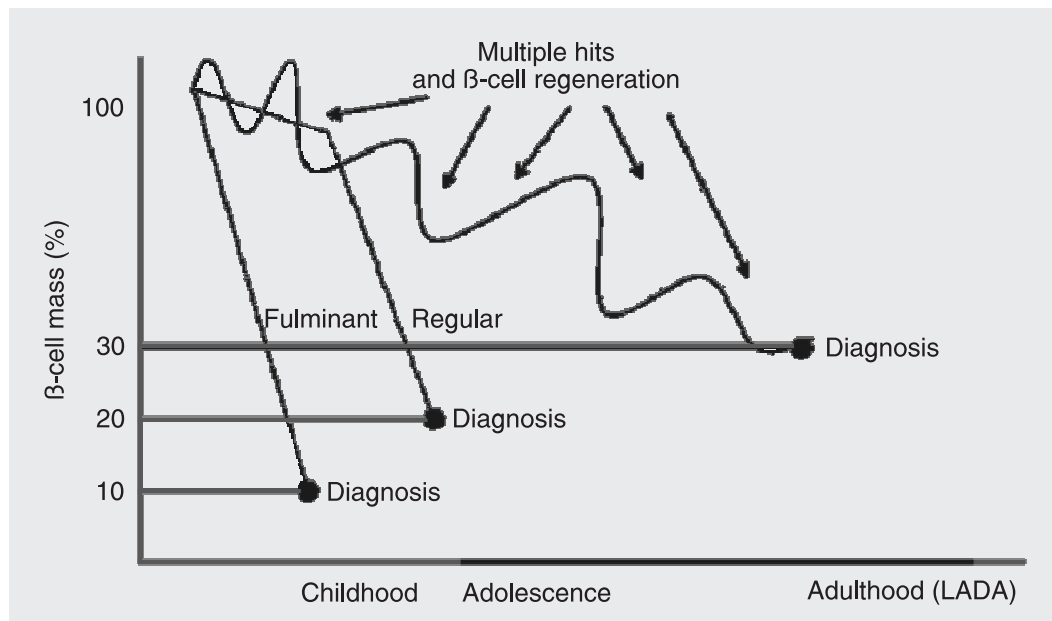

Figure 1. Rate of B-cell destruction as a function of age at clinical onset of type 1 diabetes mellitus (reproduced from Ref. 3 , with permission from the publisher).

\section{Stopping the destruction - a way to preserve $ß$-cell mass}

Subgroup analysis of the Diabetes Control and Complication Trial (DCCT) showed an important aspect related to long-term complications of diabetes, i.e., patients with initially higher serum levels of C-peptide presented a slower decline of these levels during the study and suffered less microvascular complications than patients with low or undetected levels of C-peptide. In other words, $B$-cell preservation is another important target in the management of type 1 diabetes and its related complications (7).

Preservation of $\beta$-cell mass, however, was attempted with immunosuppression long time before the DCCT. In 1981, Eliot and colleagues (8) treated recently diagnosed children with prednisone with the aim of stopping pancreatic $B$-cell destruction by the autoimmune process. Urinary C-peptide levels in the group treated with corticosteroid were significantly higher than control for one year after therapy was initiated. Subsequently, short-term studies were conducted using azathioprine $(9,10)$, azathioprine plus prednisone (11), and cyclosporine $(12,13)$ and demonstrated a slower decline (or even some improvement) in plasma C-peptide levels. In those studies, some patients experienced short periods $(<1$ year) during which they were free from insulin treatment (Table 1). The chronic toxicity of immunosuppression and the loss of the metabolic benefits after the withdrawal of the immunosuppressive agents limited the routine use of these therapies.

Recently, two studies were reported using acute immunosuppressive treatments with humanized antibodies against a T-cell antigen (CD3) for recently diagnosed type 1 diabetic patients. The first study showed that 12 patients who were treated with the antibody had better $\beta$-cell function (measured by $\mathrm{C}$-peptide levels) and lower exogenous insulin requirements after 1 year than pa- 
tients in the placebo group (14). A subsequent study on a larger sample of patients (40 in each group) showed that the effects on $B$-cell function and insulin requirements could be maintained for up to 18 months (15). However, very few patients became insulin-free in these trials.

Studies using immunosuppressive agents should be done shortly after or even before the clinical diagnosis of type 1 diabetes, since a larger B-cell mass can be preserved. In 2002, Shapiro et al. (16) showed that low doses of sirolimus $(0.1 \mathrm{mg} / \mathrm{kg})$ and tacrolimus $(0.1 \mathrm{mg} / \mathrm{kg})$ were able to reduce insulitis, preserving pancreatic insulin content and preventing diabetes in female non-obese diabetic (NOD) mice ( $8 \%$ diabetes incidence at 35 weeks vs $66 \%$ in vehicle-treated mice). The rationale of the immunosuppressive treatment is focused on stopping autoimmune aggression to the endocrine pancreas, facilitating its natural reconstitution and maintaining the residual functional capacity of the B-cell mass (see below). The same goal can be reached by a different mechanism at least transiently in early onset type 1 diabetes mellitus (DM1) treated with intensive insulin therapy (17), somatostatin (18) or diazoxide (19). These therapies preserve ß-cell reserve, inhibiting insulin secretion and providing a rest to $\beta$-cell activity.

As overt type 1 diabetes is preceded by a chronic phase in which T-cells and other mononuclear cells infiltrate the islets, some trials have analyzed the impact of certain drugs on the prevention of $\beta$-cell loss early in the preclinical phase. In these trials, drugs such as oral and parenteral insulin and oral nicotinamide were unable to delay the onset of diabetes and to prevent insulin use (2022). In 2004, a Finnish birth-cohort study was conducted to analyze the effect of dietary vitamin $\mathrm{D}$ supplementation on the incidence of type 1 diabetes. Children who regularly took the recommended dose of vitamin D (2000 IU daily) during the first year of life had a risk reduction of $0.22(0.05-0.89)$ compared with those who regularly received less than the recommended amount. Thus, vitamin D seems to promote a protective action against pancreatic ß-cell immune-mediated destruction (23). Immunosuppressive treatments have not yet been employed in primary prevention trials.

In late 2003, our research group started a phase I/II study of high dose immunosuppression with intravenous cyclophosphamide plus antithymocyte globulin followed by autologous hematopoietic stem cell transplantation for patients with new-onset type 1 diabetes. The aim of this treatment was to stop the autoimmune destruction of B-cells with immunosuppressive drugs and to "reset" the deleterious immunologic system to a normally reconstituted one with autologous hematopoietic stem cells (24). This therapy is being successfully used in other autoimmune diseases such as systemic lupus

$\begin{aligned} & \text { Table 1. Effect of different immunosuppressive treatments on insulin-free time in patients with newly diag- } \\
& \text { nosed type } 1 \text { diabetes mellitus. }\end{aligned}$
\begin{tabular}{lccc} 
Immunosuppressive regimen & Duration of treatment & $\begin{array}{c}\text { Number of patients free } \\
\text { from the necessity for insulina }\end{array}$ & $\begin{array}{c}\text { Insulin-free } \\
\text { period (mean) }\end{array}$ \\
\hline Prednisone (7) & 12 months & $4 / 17$ & 3 months \\
Prednisone + azathioprine (10) & 12 months & $10 / 20$ & 1 week \\
Azathioprine (8) & 12 months & $7 / 13$ & 12 months \\
Azathioprine (9) & 12 months & $0 / 24$ & 0 \\
Cyclosporin (11) & $6-24$ months & $53 / 122$ & 10 months
\end{tabular}

aNumber of patients free from the necessity for insulin/number of treated patients. bone patient remained in remission for 35 months. The numbers in parentheses refer to the reference describing the research. 
erythematous and multiple sclerosis (25). The exact mechanism of action of autologous hematopoietic stem cell transplantation is unclear, but it may shift the balance between destructive immunity and tolerance through yet undefined mechanisms such as clonal exhaustion, suppressor cells, immune indifference, cytokine alterations, changes in T- or B-cell clonality or changes in immunodominant autoantigens (25). The results of transplantation are monitored by endocrine (HbA1c, C-peptide levels and dose of insulin $\mathrm{kg}^{-1} \mathrm{day}^{-1}$ ) and immunologic parameters (lymphocyte subsets, cytokine production, T-cell receptor diversity, and humoral and cellular autoreactivity against pancreatic $\beta$-cells). Severe adverse effects and mortality are expected to be very low in this population of young patients with no previous morbidity except for DM1 (24). Preliminary results obtained with 13 patients are encouraging but they have not yet been published in full (26).

New clinical trials using various forms of immunosuppression (mycophenolate mofetil, anti-IL-2 receptor antibodies, anti-CD20 antibody, or anti-thymocyte globulin) for DM1, without infusion of stem cells, started recently or are prepared to start soon.

\section{ß-cell regeneration: is it possible?}

Differentiated B-cells first appear around the 13th embryonic day (at the onset of the secondary transition), a phase of pancreatic organogenesis during which endocrine cells detach from the exocrine matrix, increase in number and reorganize to form mature islets. Islet growth continues after birth resulting from a combination of hypertrophy and hyperplasia (27).

The maintenance of B-cell mass is the result of a dynamic state consisting of neogenesis, proliferation and apoptosis (28). This is a physiological process whose objective is to guarantee the harmony of glucose homeostasis in the presence of challenges experi- enced after birth such as obesity and other states of insulin resistance $(29,30)$.

The vast majority of studies analyzing pancreatic regeneration were conducted on rodents (see below). Thus, in 1983, BonnerWeir and colleagues demonstrated that young near-totally pancreatectomized rats presented an eight-week recuperation of $27 \%$ of pancreas weight and $42 \%$ of the endocrine pancreas. Quantitative measurements estimated B-cell turnover in adult rat islets to be as high as $3 \%$ per day (31). Some sporadic cases in humans are impressive in this regard: for example, a 39-year-old type 1 diabetic patient submitted to simultaneous pancreaskidney transplantation was referred for treatment of an abdominal incision herniation 2 years after the initial procedure. A regimen with tacrolimus, prednisolone and mycophenolate was used post-transplantation and good glycemic control was achieved without exogenous insulin. At the time of the corrective surgery, a native pancreas biopsy showed that the percent of B-cells was 4-fold higher than that observed in long-term type 1 diabetic patients conventionally treated with insulin (32).

In light of recent discoveries demonstrating the regenerative potential of the pancreas, which cells could be the precursors of adult B-cells?

\section{Probable precursors of adult ß-cells}

A stem cell is defined by two properties. First, it is a cell that can divide indefinitely, producing a population of identical offspring. Second, stem cells can undergo an asymmetric division to produce two dissimilar daughter cells: one is identical to the parent and continues to contribute to the original stem cell line and the other follows variable pathways. This cell contains a different set of genetic instructions (resulting in an alternative pattern of gene expression) and is characterized by a reduced proliferative capacity and more restricted developmental 
potential than its parents $(33,34)$. Eventually a stem cell becomes a "progenitor" or "precursor" cell, committed to produce one or a few terminally differentiated cells such as neurons or muscle cells (35) (Table 2). The clonal isolation of putative pancreatic precursors has been an elusive objective of researchers who look for a more complete knowledge of B-cell physiology and for new replacement strategies for DM1.

\section{Pancreas-derived stem cells}

Many studies have looked for $\beta$-cell precursors in pancreatic tissue. Georgia and Bhushan (36) demonstrated that cyclin D2 expression in the endocrine pancreas coincides with a massive increase in islet mass, with $\beta$-cell replication being the main mechanism for the maintenance of $\beta$-cell mass. Using cyclin $D 2^{-/-}$mice, $\beta$-cell replication was reduced 4 -fold and cyclin $\mathrm{D}^{-/-}$mice were glucose intolerant. These results suggested that cyclin D2 plays a key role in regulating the transition of $B$-cells from a state of quiescence to replication. In addition, many other investigators support the hypothesis of self-replication as the main source of B-cell mass. Their analysis shows that pre-existing $B$-cells, rather than pluripotent stem cells, are the major source of new B-cells during adult life and after pancreatectomy in mice $(37,38)$. On the other hand, in other studies, the increase in $\beta$-cell mass in adult mice is considered to result from differentiation of adult multipotent precursors. Thus, Seaberg and colleagues (35) reported the isolation of pancreas-derived multipotent precursors from pancreatic islets and ducts. These cells proliferate in vitro to form individual clonal colonies of neurons and glial cells, pancreatic endocrine $\alpha-, \beta-, \delta$-cells and pancreatic exocrine cells. The in vitro proliferated $\beta$-cells were shown to be able to produce insulin. The pancreas-derived multipotent precursors did not express markers of embryonic stem cells or genes suggestive of mesodermal or neural crest origin. Therefore, they could represent a previously unidentified adult intrinsic pancreatic precursor proposed by other investigators using flow-cytometric cell sorting (39).

Lechner et al. (40) reported that cells expressing the intermediate filament protein nestin, a marker of neural stem cells, can be isolated from human and rodent islets and expanded extensively in vitro. Insulin, glucagon, and pancreatic duodenal homeobox-

Table 2. Stem cell nomenclature.

\begin{tabular}{|c|c|}
\hline Cell line & Homogeneous population of cells capable of self renewal. \\
\hline Cloned cell line & Population of cells that derives from replication of a single cell. \\
\hline Stem cell & Cell that can divide indefinitely to produce differentiated tissues and of identical stem cells. \\
\hline Zygote & Diploid cell resulting from the fusion of male and female gametes. \\
\hline Morula & Spheroidal mass of cells resulting from early cleavage divisions of the zygote. \\
\hline Blastocyst & Four- to five-day-old embryo formed prior to implantation in the uterus; consisted of only a few undifferentiated stem cells. \\
\hline Embryoid body & Cluster of embryonic cells presented in cultures of stem cells or in tumors. \\
\hline Totipotent cell & $\begin{array}{l}\text { Cell committed to a specific lineage that is capable of giving rise to all cells and tissues, including extraembryonic tissues. } \\
\text { Example: blastomeres from the morula. }\end{array}$ \\
\hline Pluripotent cell & $\begin{array}{l}\text { Cell not committed to a specific lineage that may differentiate into all tissues, with exception of extraembryonic tissues. } \\
\text { Example: cells from the inner cell mass of the blastocyst. }\end{array}$ \\
\hline Multipotent cell & $\begin{array}{l}\text { Progenitor cell that can give rise to diverse cell types in response to appropriate environmental cues. } \\
\text { Example: adult bone marrow mesenchymal stem cells. }\end{array}$ \\
\hline Progenitor cell & $\begin{array}{l}\text { Parent cell that is committed to dividing and multiplying in order to form a specific cell type. } \\
\text { Examples: hematopoietic cells committed to the differentiation of granulocytes (CFU-GM), erythrocytes (BFU-E and } \\
\text { CFU-E), platelets (CFU-Meg). }\end{array}$ \\
\hline
\end{tabular}


1 protein/insulin promoter factor-1 (IPF-1/ IPF-1) expression, as well as low-level insulin secretion, can be detected in cultures of nestin-positive islet-derived stem cells after the addition of differentiating cytokines and growth factors. These cells also form insulin-producing islet-like clusters in vitro, a process that is markedly enhanced by the addition of the insulinotropic hormone glucagon-like peptide- 1 .

Few studies, however, have been conducted on human pancreatic tissues. In 2000, Bonner-Weir et al. (41), using fractions of digested human pancreas enriched for ductal tissue, generated in vitro insulin-producing islet-like clusters. When plastic adherent cells from these preparations were overlaid with an inert matrix (Matrigel), they formed cysts and clusters (cultured human islet buds). Most cells in these aggregates were positive for the ductal marker cytokeratin 19 and others showed immunoreactivity for insulin and other islet hormones. The insulin content of the cultures increased over time, and a low level of glucose-responsive insulin secretion was observed in vitro. However, the capacity to expand the cultivated tissue was limited.

\section{Bone marrow and umbilical cord blood}

Although the existence of stem cells in adult organs appears to be relatively well accepted, the intriguing question is how did these cells actually get there? The first hypothesis is that they represent a population of cells that are preserved throughout development in every single organ. These cells appear to have maintained many properties of pluripotential blastocyst cells and could participate in local tissue repair throughout the lifespan of the organism. A second hypothesis is that a distant source such as bone marrow may contain a self-renewing population of multipotent stem cells that are continuously released into the circulation. It is tempting to speculate that stem cells are an essential component of this circulating bone marrow surveillance system and that they are prepared to home to areas of injured tissues to participate in tissue repair and regeneration (42).

Ianus and colleagues (43) demonstrated an extra-pancreatic source of B-cells that may play a role in the adaptation of $\beta$-cell mass in response to physiological and environmental stimuli. In this study, bone marrow cells that selectively expressed the enhanced green fluorescent protein (EGFP) if the insulin gene was actively transcribed were transplanted into lethally irradiated recipient mice and gave rise to EGFP-positive insulin-producing cells in pancreatic islets. Through a genetic approach, the authors ruled out cell fusion as the mechanism for EGFP-positive cells with islet-like characteristics. Moreover, these cells seemed to be functional since glucose and incretins stimulated insulin secretion.

The subpopulation of bone marrow cells that can give rise to insulin-positive islet cells is not yet known. One candidate is the bone marrow hematopoietic stem cell that, in experiments of liver regeneration, has been shown to be able to differentiate into hepatocytes $(44,45)$ and thus may be the source of differentiated B-cells. However, Kang et al. (46) showed that hematopoietic stem cell transplantation prevents diabetes in NOD mice but does not contribute to significant islet cell regeneration once the disease is established. Other more likely candidates recently described are the multipotential adult progenitor cells (MAPCs) (47) or mesenchymal stem cells. MAPCs exhibit remarkable plasticity with the ability to differentiate into cells with mesodermal, neuroectodermal and endodermal characteristics in vitro. In 2004, after isolation of MAPCs from Wistar rat bone marrow, Chen et al. (48) induced in vitro $\beta$-cell differentiation under appropriate conditions. These cells presented glucose-dependent insulin secre- 
tion in vitro and, when transplanted into streptozotocin-induced diabetic rats, could down-regulate blood glucose levels.

Umbilical cord blood (UCB) is another source of stem cells with the potential to promote in vivo $B$-cell regeneration. In fact, in a xenogenic model of stem cell transplantation, human mononuclear UCB cells were able to reduce blood glucose levels and increase survival in mouse models of DM1 (49) and DM2 (50). In DM2 animals, UCB stem cell infusion also improved renal abnormalities caused by diabetes, suggesting a regenerative action on the renal parenchyma. However, there is no indication of the type of stem cells or the mechanism responsible for the clinical effect.

The possible role of adult stem cells derived either from UCB or bone marrow on $\beta$ cell regeneration led to the organization of some clinical trials to use those cells to treat human DM. In the San Nicolas Clinic, Argentina, adult bone marrow mononuclear cells are being injected into the pancreas of DM1 and DM2 patients by arteriography without any additional treatment. The results have not been fully published but have shown improvement of metabolic parameters and a reduced use of antidiabetic drugs more pronounced in DM2 than in DM1 patients. Proposed mechanisms are stimulation of angiogenesis and B-cell regeneration by stem cells (Fernandez-Viña R, personal communication, and Ref. 51). On the other hand, at the University of South Florida, USA, autologous UCB cells cryopreserved at birth from infants that become DM1 patients later in life are injected back into these children intravenously without previous immunosuppression. The expectation is that UCB cells would migrate preferentially to the damaged pancreas, either inducing the proliferation of insulin-producing islets, providing protection to existing islets by modulating the autoimmune process, or possibly differentiating into islet cells. Eight patients have been treated in this manner, apparently with positive responses (Haller $\mathrm{M}$ and Wingard $\mathrm{J}$, personal communication).

\section{Hepatic oval cells}

Pancreas and liver have a close anatomic association starting from the primitive foregut during embryogenesis and this fact has prompted attempts to isolate pancreatic progenitor cells from the liver, especially the hepatic oval cells. Oval cells are considered to be hepatic stem cells that can give rise to hepatocytes and bile duct cells (52). Yang et al. (53), using in vitro proliferation of these cells, obtained islet-like clusters that could express several endocrine hormones including insulin. In the same publication, a preliminary in vivo study described the successful reversal of diabetes in streptozotocintreated NOD mice with severe combined immunodeficiency (NOD-SCID) using hepatic stem cells.

\section{Embryonic stem cells}

Embryonic stem cells (ESC) are pluripotent cell lines derived from the inner cell mass of blastocyst stage embryos and their differentiation in culture may reproduce characteristics of early embryonic development. Pancreatic and islet cell replacement are currently considered to be the only curative therapies for type 1 diabetes. However, the shortage of human donations is a primary obstacle for these approaches, making ESC a promising source of $\beta$-cell generation in the near future in countries where their use is permitted.

Assady et al. (54), using human ESC, demonstrated the spontaneous in vitro differentiation of $\mathrm{H} 9$ cells with specific characteristics of B-cells under both adherent and suspension culture conditions. After embryoid body development, $3 \%$ of all cells stained positively for insulin at a maximal density demonstrated by markers of $\beta$-cell identity such as glucose transporter protein GLUT2 
and glucokinase genes, Pdx-1/Ipf-1 and neurogenin-3 transcription factors. Functional analyses indicated secretion of insulin into the medium.

Other studies have used cell-trapping systems or various growth factors to obtain insulin-secreting clones from undifferentiated ESC of mice. Soria et al. (55) developed a gene construction that allows the expression of a neomycin selection system under the control of regulatory regions of the human insulin gene. The chimeric gene also contained a hygromycin resistance gene used to select transfected cells. A resulting clone displayed regulated hormone secretion in vitro in the presence of various secretagogues. After the in vitro isolation of clusters of differentiated B-cells from ESC, these cells were implanted in the spleen of streptozotocin-induced diabetic animals. Normoglycemia and normal body weight were restored after 1 and 4 weeks, respectively.

Based on several recent reports claiming the generation of insulin-producing cells from ESC, Hansson et al. (56) investigated the properties of these insulin-containing progenitors. In their study they found that, although differentiated cells containing immunoreactive insulin were isolated, they did not contain proinsulin-derived C-peptide. Furthermore, in spite of variable insulin release from these cells upon glucose addition, C-peptide release was never detected. They suggested that C-peptide biosynthesis and secretion should be demonstrated in order to claim insulin production from an ESC progeny.

The potential of ESC to regenerate pancreatic B-cells attracted the attention of biotechnological companies interested in developing embryonic cell lines to be used by diabetic patients (57) and of for-profit clinics that are injecting embryonic stem cells from 4-8-week embryos into type 2 diabetic patients. Favorable responses were reported in abstract form $(58,59)$.

Much effort for the identification of $\mathrm{B}$ cell precursors has been made not only with the aim of understanding the physiology of islet regeneration but also as an alternative way to produce $\beta$-cells to be used in protocols of islet transplantation. Precursor cells implicated in the regeneration process include ESC, pancreas-derived multipotent precursors, ductal cells, hematopoietic stem cells, mesenchymal stem cells, hepatic oval cells, and mature B-cells. Whatever the source of $\beta$-cells, immunosuppressive regimens associated or not with stem cell infusion seem to facilitate these endogenous mechanisms of $\beta$-cell regeneration in early-onset disease. For patients with a longer time of diagnosis of type 1 diabetes, inactivation of the autoimmune response should be associated with strategies of B-cell regeneration, since a much larger $\beta$-cell mass has been destroyed in these patients. For this purpose, clinical trials using stem cells derived from embryonic tissues, umbilical cord blood or adult bone marrow are underway.

\section{References}

1. American Diabetes Association. Diagnosis and classification of diabetes mellitus. Diabetes Care 2004; 27 (Suppl 1): S5-S10.

2. Notkins AL, Lernmark A. Autoimmune type 1 diabetes: resolved and unresolved issues. J Clin Invest 2001; 108: 1247-1252.

3. Pozzilli P, Di Mario U. Autoimmune diabetes not requiring insulin at diagnosis (latent autoimmune diabetes of the adult): definition, characterization, and potential prevention. Diabetes Care 2001; 24: 14601467.

4. Palmer JP, Fleming GA, Greenbaum CJ, Herold KC, Jansa LD, Kolb $\mathrm{H}$, et al. C-peptide is the appropriate outcome measure for type 1 diabetes clinical trials to preserve beta-cell function: report of an ADA workshop, 21-22 October 2001. Diabetes 2004; 53: 250-264.

5. Writing Team for the Diabetes Control and Complications Trial/ Epidemiology of Diabetes Interventions and Complications Research Group. Effect of intensive therapy on the microvascular complications of type 1 diabetes mellitus. JAMA 2002; 287: 25632569.

6. The Diabetes Control and Complications Trial Research Group. The effect of intensive treatment of diabetes on the development and progression of long term complications in insulin-dependent diabe- 
tes mellitus. N Engl J Med 1993; 389: 977-986.

7. The Diabetes Control and Complications Trial Research Group. Effect of intensive therapy on residual beta-cell function in patients with type 1 diabetes in the diabetes control and complications trial. A randomized, controlled trial. Ann Intern Med 1998; 128: 517-523.

8. Eliot RB, Berryman CC, Crossley JR, James AG. Partial preservation of pancreatic B-cell function in children with diabetes. Lancet 1981; 19: 631-632.

9. Harrison LC, Colman PG, Dean B, Baxter R, Martin FI. Increase in remission rate in newly diagnosed type I diabetic subjects treated with azathioprine. Diabetes 1985; 34: 1306-1308.

10. Cook JJ, Hudson I, Harrison LC, Dean B, Colman PG, Werther GA, et al. Double-blind controlled trial of azathioprine in children with newly diagnosed type I diabetes. Diabetes 1989; 38: 779-783.

11. Silverstein J, Maclaren N, Riley W, Spillar R, Radjenovic D, Johnson S. Immunosuppression with azathioprine and prednisone in recentonset insulin-dependent diabetes mellitus. N Engl J Med 1988; 319: 599-604.

12. Assan R, Feutren G, Sirmai J, Laborie C, Boitard C, Vexiau P, et al. Plasma C-peptide levels and clinical remissions in recent-onset type I diabetic patients treated with cyclosporin A and insulin. Diabetes 1990; 39: 768-774.

13. Bougneres PF, Landais P, Boisson C, Carel JC, Frament N, Boitard $\mathrm{C}$, et al. Limited duration of remission of insulin dependency in children with recent overt type I diabetes treated with low-dose cyclosporin. Diabetes 1990; 39: 1264-1272.

14. Herold KC, Hagopian W, Auger JA, Poumian-Ruiz E, Taylor L, Donaldson D, et al. Anti-CD3 monoclonal antibody in new-onset type 1 diabetes mellitus. N Engl J Med 2002; 346: 1692-1698.

15. Keymeulen B, Vandemeulebroucke E, Ziegler AG, Mathieu C, Kaufman L, Hale G, et al. Insulin needs after CD3-antibody therapy in new-onset type 1 diabetes. N Engl J Med 2005; 352: 2598-2608.

16. Shapiro AM, Suarez-Pinzon WL, Power R, Rabinovitch A. Combination therapy with low dose sirolimus and tacrolimus is synergistic in preventing spontaneous and recurrent autoimmune diabetes in nonobese diabetic mice. Diabetologia 2002; 45: 224-230.

17. Shah SC, Malone JI, Simpson NE. A randomized trial of intensive insulin therapy in newly diagnosed insulin-dependent diabetes mellitus. N Engl J Med 1989; 320: 550-554.

18. Grunt JA, al-Hakim H, Willoughby L, Howard CP. A randomized trial of a somatostatin analog for preserving beta cell function in children with insulin dependent diabetes mellitus. J Pediatr Endocrinol 1994; 7: 331-334.

19. Ortqvist E, Bjork E, Wallensteen M, Ludvigsson J, Aman J, Johansson C, et al. Temporary preservation of beta-cell function by diazoxide treatment in childhood type 1 diabetes. Diabetes Care 2004; 27: 2191-2197.

20. Gale EA, Bingley PJ, Emmett CL, Collier T. European Nicotinamide Diabetes Intervention Trial (ENDIT): a randomised controlled trial of intervention before the onset of type 1 diabetes. Lancet 2004; 363: 925-931.

21. Chaillous L, Lefevre H, Thivolet C, Boitard C, Lahlou N, tlan-Gepner $\mathrm{C}$, et al. Oral insulin administration and residual beta-cell function in recent-onset type 1 diabetes: a multicentre randomised controlled trial. Diabete Insuline Orale group. Lancet 2000; 356: 545-549.

22. Diabetes Prevention Trial - Type 1 Diabetes Study Group. Effects of insulin in relatives of patients with type 1 diabetes mellitus. $N$ Engl $J$ Med 2002; 346: 1685-1691.

23. Hypponen E, Laara E, Reunanen A, Jarvelin MR, Virtanen SM. Intake of vitamin $\mathrm{D}$ and risk of type 1 diabetes: a birth-cohort study. Lancet 2001; 358: 1500-1503.
24. Voltarelli JC, Burt RK, Kenyon N, Kaufman DB, Squiers E. Hematopoietic stem cell transplantation as treatment for type 1 diabetes. In: Burt R, Marmont A (Editors), Stem cell therapy for autoimmmune diseases. Georgetown: Landes Bioscience; 2004.

25. Burt RK, Slavin S, Burns WH, Marmont AM. Induction of tolerance in autoimmune diseases by hematopoietic stem cell transplantation: getting closer to a cure? Blood 2002; 99: 768-784.

26. Voltarelli J, Couri C, Oliveira M, Stracieri A, Moraes D, Coutinho M, et al. Autologous hematopoietic stem cell transplantation for type I diabetes mellitus. Bone Marrow Transplant 2006; 37 (Suppl 1): S16.

27. Lee VM, Stoffel M. Bone marrow: an extra-pancreatic hideout for the elusive pancreatic stem cell? J Clin Invest 2003; 111: 799-801.

28. Bonner-Weir S, Sharma A. Pancreatic stem cells. J Pathol 2002; 197: 519-526.

29. Swenne I. Pancreatic beta-cell growth and diabetes mellitus. Diabetologia 1992; 35: 193-201.

30. Fernandes A, King LC, Guz Y, Stein R, Wright CV, Teitelman G. Differentiation of new insulin-producing cells is induced by injury in adult pancreatic islets. Endocrinology 1997; 138: 1750-1762.

31. Finegood DT, Scaglia L, Bonner-Weir S. Dynamics of beta-cell mass in the growing rat pancreas. Estimation with a simple mathematical model. Diabetes 1995; 44: 249-256.

32. Kuroda A, Yamasaki $Y$, Imagawa A. Beta-cell regeneration in a patient with type 1 diabetes mellitus who was receiving immunosuppressive therapy. Ann Intern Med 2003; 139: W81.

33. Fischbach GD, Fischbach RL. Stem cells: science, policy, and ethics. J Clin Invest 2004; 114: 1364-1370.

34. Wagers AJ, Weissman IL. Plasticity of adult stem cells. Cell 2004; 116: $639-648$.

35. Seaberg RM, Smukler SR, Kieffer TJ, Enikolopov G, Asghar Z, Wheeler MB, et al. Clonal identification of multipotent precursors from adult mouse pancreas that generate neural and pancreatic lineages. Nat Biotechnol 2004; 22: 1115-1124.

36. Georgia S, Bhushan A. Beta cell replication is the primary mechanism for maintaining postnatal beta cell mass. J Clin Invest 2004; 114: 963-968.

37. Dor Y, Brown J, Martinez OI, Melton DA. Adult pancreatic beta-cells are formed by self-duplication rather than stem-cell differentiation. Nature 2004; 429: 41-46.

38. Levine F, Mercola M. No pancreatic endocrine stem cells? $N$ Engl $J$ Med 2004; 351: 1024-1026.

39. Suzuki A, Nakauchi $H$, Taniguchi $H$. Prospective isolation of multipotent pancreatic progenitors using flow-cytometric cell sorting. Diabetes 2004; 53: 2143-2152.

40. Lechner A, Leech CA, Abraham EJ, Nolan AL, Habener JF. Nestinpositive progenitor cells derived from adult human pancreatic islets of Langerhans contain side population (SP) cells defined by expression of the ABCG2 (BCRP1) ATP-binding cassette transporter. Biochem Biophys Res Commun 2002; 293: 670-674.

41. Bonner-Weir S, Taneja M, Weir GC, Tatarkiewicz K, Song KH, Sharma A, et al. In vitro cultivation of human islets from expanded ductal tissue. Proc Natl Acad Sci U S A 2000; 97: 7999-8004.

42. Lechner A, Habener JF. Stem/progenitor cells derived from adult tissues: potential for the treatment of diabetes mellitus. Am J Physiol Endocrinol Metab 2003; 284: E259-E266.

43. Ianus A, Holz GG, Theise ND, Hussain MA. In vivo derivation of glucose-competent pancreatic endocrine cells from bone marrow without evidence of cell fusion. J Clin Invest 2003; 111: 843-850.

44. Lagasse E, Connors H, Al-Dhalimy M, Reitsma M, Dohse M, Osborne $\mathrm{L}$, et al. Purified hematopoietic stem cells can differentiate into hepatocytes in vivo. Nat Med 2000; 6: 1229-1234. 
45. Theise ND, Badve S, Saxena R, Henegariu O, Sell S, Crawford JM, et al. Derivation of hepatocytes from bone marrow cells in mice after radiation-induced myeloablation. Hepatology 2000; 31: 235-240.

46. Kang EM, Zickler PP, Burns S, Langemeijer SM, Brenner S, Phang $\mathrm{OA}$, et al. Hematopoietic stem cell transplantation prevents diabetes in NOD mice but does not contribute to significant islet cell regeneration once disease is established. Exp Hematol 2005; 33: 699705.

47. Jiang $Y$, Jahagirdar $B N$, Reinhardt $R L$, Schwartz RE, Keene $C D$, Ortiz-Gonzalez XR, et al. Pluripotency of mesenchymal stem cells derived from adult marrow. Nature 2002; 418: 41-49.

48. Chen LB, Jiang XB, Yang L. Differentiation of rat marrow mesenchymal stem cells into pancreatic islet beta-cells. World J Gastroenterol 2004; 10: 3016-3020.

49. Ende N, Chen R, Reddi AS. Effect of human umbilical cord blood cells on glycemia and insulitis in type 1 diabetic mice. Biochem Biophys Res Commun 2004; 325: 665-669.

50. Ende N, Chen R, Reddi AS. Transplantation of human umbilical cord blood cells improves glycemia and glomerular hypertrophy in type 2 diabetic mice. Biochem Biophys Res Commun 2004; 321: 168-171.

51. Fernandez-Viña R, Saslavsky J, Andrin O, Sosa N, Swirido P, Vrsalovick F, et al. Feasibility of implant autologous stem cells with endovascular technique in diabetes mellitus. Cytotherapy 2004; 7 (Suppl 1): Abstract \#37.
52. Petersen BE, Goff JP, Greenberger JS, Michalopoulos GK. Hepatic oval cells express the hematopoietic stem cell marker Thy-1 in the rat. Hepatology 1998; 27: 433-445.

53. Yang L, Li S, Hatch H, Ahrens K, Cornelius JG, Petersen BE, et al. In vitro trans-differentiation of adult hepatic stem cells into pancreatic endocrine hormone-producing cells. Proc Natl Acad Sci U S A 2002; 99: 8078-8083.

54. Assady S, Maor G, Amit M, Itskovitz-Eldor J, Skorecki KL, Tzukerman M. Insulin production by human embryonic stem cells. Diabetes 2001; 50: 1691-1697.

55. Soria B, Roche E, Berna G, Leon-Quinto T, Reig JA, Martin F. Insulin-secreting cells derived from embryonic stem cells normalize glycemia in streptozotocin-induced diabetic mice. Diabetes 2000; 49: 157-162.

56. Hansson M, Tonning A, Frandsen U, Petri A, Rajagopal J, Englund $\mathrm{MC}$, et al. Artifactual insulin release from differentiated embryonic stem cells. Diabetes 2004; 53: 2603-2609.

57. Sinden JD. ReNeuron Group plc. Regenerative Med 2006; 1: 143 147.

58. Smikodub OI, Noritskaya AV. Embryonic stem cells in new onset type 2 diabetes mellitus. Cytotherapy 2004; 6: 402 (Abstract).

59. Smikodub OI, Noritskaya AV. Embryonic stem cells in pernicious decompensated type 2 diabetes mellitus. Cytotherapy 2004; 6: 402 403 (Abstract). 